\title{
Maria Careri, Christine Ruby, Ian Short, avec la collaboration de Terry Nixon et de Patricia Stirnemann, Livres et écritures en français et en occitan au XII siècle. Catalogue illustré
}

\section{Maria Colombo Timelli}

\section{(2) OpenEdition Journals}

Édition électronique

URL : http://journals.openedition.org/studifrancesi/2048

DOI : $10.4000 /$ studifrancesi.2048

ISSN : 2421-5856

Éditeur

Rosenberg \& Sellier

\section{Édition imprimée}

Date de publication : 1 avril 2014

Pagination : 113

ISSN : 0039-2944

\section{Référence électronique}

Maria Colombo Timelli, « Maria Careri, Christine Ruby, lan Short, avec la collaboration de Terry Nixon et de Patricia Stirnemann, Livres et écritures en français et en occitan au xI" siècle. Catalogue illustré ", Studi Francesi [En ligne], 172 (LVIII | I) | 2014, mis en ligne le 01 avril 2014, consulté le 18 septembre 2020. URL : http://journals.openedition.org/studifrancesi/2048 ; DOI : https://doi.org/10.4000/ studifrancesi.2048

Ce document a été généré automatiquement le 18 septembre 2020.

\section{(†) $\odot$

Studi Francesi è distribuita con Licenza Creative Commons Attribuzione - Non commerciale - Non opere derivate 4.0 Internazionale. 


\title{
Maria Careri, Christine Ruby, Ian Short, avec la collaboration de Terry Nixon et de Patricia Stirnemann, Livres et écritures en français et en occitan au XII siècle. Catalogue illustré
}

\author{
Maria Colombo Timelli
}

\section{RÉFÉRENCE}

MARIA CARERI, CHRISTINE RUBY, IAN SHORT, avec la collaboration de Terry NIXON et de Patricia STIRNEMANN, Livres et écritures en français et en occitan au XII ${ }^{\mathrm{e}}$ siècle. Catalogue illustré, Roma, Viella, 2011 («Scritture e libri del medioevo», 8), pp. 274.

1 Ce répertoire représente la réalisation d'un projet ancien, conçu par Brian Woledge il y a une cinquantaine d'années, continué par Ian Short puis par Terry Nixon, et maintenant mené à bien grâce aux efforts d'une équipe qui a pu profiter de la documentation réunie à l'IRHT et examiner directement les manuscrits en question; ce travail de longue haleine a permis enfin de passer d'une liste relativement large et provisoire à un catalogue raisonné et sans doute définitif comptant une centaine de manuscrits.

2 Les notices, qui constituent évidemment le cœur de ce beau livre, sont précédées d'une introduction substantielle où les auteurs illustrent rapidement l'histoire du projet et ses homologues (catalogues existants pour les manuscrits latins et pour les autres langues vernaculaires) et surtout ils s'expriment sur les critères suivis pour l'établissement du corpus. Il s'agit d'abord d'expliquer le choix des manuscrits retenus et les limites de l'ensemble, déterminées bien entendu par la datation (souvent problématique, fondée quasi exclusivement sur des éléments internes tels que 
l'écriture) et par le contenu (présence de la langue française ou occitane, même si pour celle-ci ont été exclus les documents uniquement administratifs). Après cette section dûment informative, c'est un premier bilan du contenu des notices qui est offert; les données recueillies permettent en effet déjà d'établir un panoramique des dates et des zones de production des manuscrits (graphique p. xxxiI et carte $p$. xxxiv) et une typologie particulièrement intéressante: si les fragments abondent (27 mss sur 102), la langue vernaculaire est présente sous la forme d'ajout dans 17 manuscrits latins; 33 manuscrits représentent des miscellanées bilingues latin / langue vernaculaire, alors que 27 ne contiennent que du français. Quelques manuscrits font l'objet de commentaires plus approfondis, entre autres le célèbre Digby 23 (Chanson de Roland, ici n. 57), ou le Psautier d'Oxford (n. 60). L'analyse fait aussi ressortir le nombre important d'unica, surtout des textes épiques: outre le Roland, Gormont et Isembart, Pèlerinage de Charlemagne, Chanson de Guillaume. Un classement typologique permet encore de reconnaître: 40 textes de littérature de récréation, 56 textes à caractère religieux, 38 de littérature scientifique (pp. XXXIX-XL), présentés en détail aux pp. XL-XLVII.

Une section importante de l'Introduction est consacrée aux aspects matériels: écritures (voir aussi le Glossaire paléographique, p. 231), abréviations, accents, disposition des textes en vers et ponctuation, décoration; ces remarques prouvent une fois de plus le devoir qui revient à tout philologue - et on serait tenté de dire à tout médiéviste - de prendre en compte ce qui a trait à la transmission matérielle des textes.

4 Les notices, au nombre de 97 pour un total de 102 unités textuelles, occupent 225 pages; présentées selon l'ordre alphabétique des lieux de conservation, elles comprennent les champs suivants: cote, date, origine géographique, titre, liste des textes, description codicologique, écriture, mise en texte et décoration, scripta, notes, bibliographie (pour les détails, on se rapportera à l'Introduction, pp. Xxx-XxxI); elles sont toutes accompagnées de la reproduction photographique d'un feuillet en noir et blanc (l'échelle, entre $50 \%$ et $100 \%$, est indiquée; pour les reproductions réduites, un détail $100 \%$ est aussi reproduit). L'appendice (pp. 227-230) réunit les notices très synthétiques réservées aux 19 manuscrits où la langue vulgaire est présente sous des occurrences très limitées et occasionnelles. La bibliographie (pp. 233-247) est suivie de nombreux index: auteurs et textes (pp. 249-253), auteurs modernes et textes divers (pp. 255-259), lieux (pp. 261-262), manuscrits (pp. 263-270), références photographiques (pp. 271-274).

Un tel répertoire représente non seulement l'aboutissement d'une recherche de grande envergure: il constituera nécessairement la base de toute recherche ultérieure sur les textes transmis par des témoins du XII ${ }^{\mathrm{e}}$ siècle; d'autre part, il pourra aussi offrir une documentation très utile pour les enseignements de littérature française médiévale, de philologie romane, d'histoire du livre manuscrit. 